\title{
Extracting Economic Signals from Central Bank Speeches
}

\author{
Maximilian Ahrens \\ University of Oxford \\ mahrensarobots.ox.ac.uk
}

\author{
Michael McMahon \\ University of Oxford \\ michael . mcmahond \\ economics.ox.ac.uk
}

\begin{abstract}
Estimating the effects of monetary policy is one of the fundamental research questions in monetary economics. Many economies are facing ultra-low interest rate environments ever since the global financial crisis of 20079. The Covid pandemic recently reinforced this situation. In the US and Europe, interest rates are close to (or even below) zero, which limits the scope of traditional monetary policy measures for central banks. Dedicated central bank communication has hence become an increasingly important tool to steer and control market expectations these days. However, incorporating central bank language directly as features into economic models is still a very nascent research area. In particular, the content and effect of central bank speeches has been mostly neglected from monetary policy modelling so far. With our paper, we aim to provide to the research community a novel, monetary policy shock series based on central bank speeches. We use a supervised topic modeling approach that can deal with text as well as numeric covariates to estimate a monetary policy signal dispersion index along three key economic dimensions: GDP, CPI and unemployment. This "dispersion shock" series is not only more frequent than series that classically focus on policy announcement dates, it also opens up the possibility of answering new questions that have up until now been difficult to analyse. For example, do markets form different expectations when facing a "cacophony of policy voices"? Our initial findings for the US point towards the fact that more dispersed or incongruent monetary policy stance communication in the build up to Federal Open Market Committee (FOMC) meetings might be associated with stronger subsequent market surprises at FOMC policy announcement time.
\end{abstract}

\section{Introduction}

Understanding the causal effect of monetary policy on economic and financial variables is one of the most fundamental empirical questions in monetary economics. An extensive branch of literature focuses on this question; a key empirical reference is Christiano et al. (2005). In this theme, we address this pivotal monetary economics question, and in particular, the effect of central bank communication. Our research question is whether we can extract and measure policy signals, uncertainty, or shocks from central bank speeches.

Monetary policy shock identification: The starting point of any attempt to understand the causal macroeconomic effects of monetary policy is to identify the unanticipated, exogenous element in monetary actions to avoid endogeneity concerns. The literature on constructing these monetary shocks is vast. Some use VAR analysis (Christiano et al., 2005), others focus on the narrative approach (Romer and Romer, 2004), and, most recently, the emphasis has been on highfrequency identification (Gürkaynak et al., 2005; Gertler and Karadi, 2015; Nakamura and Steinsson, 2018; Gertler and Horvath, 2018). These are not all the same thing. Monetary shocks from the narrative approach, such as the Romer and Romer (2004) shocks, are exogenous to macroeconomic conditions but are not immediately observed outside the Federal Open Market Committee (FOMC); highfrequency surprise measures, such as in Gertler and Karadi (2015) represent the surprise for markets but may be endogenous to macroeconomics. As Ramey (2016) stresses, the focus on deviations from the systematic response of policy, or shocks, is "a search for instruments rather than for primitive macroeconomic shocks". However, essentially all approaches use changes in actual policy rates as part of the identification strategy. Empirically, though, there is very little surprise in monetary policy announcements: the average change in the Fed Fund futures market around announcements since the 1990 s is only 2.7 basis points. To the extent that central bank communication between meetings 
shapes expectations of subsequent policy decisions, it contains the true surprises. What is more, a pure focus on central bank meetings only provides a rather infrequent updating cycle.

NLP-based central bank speech analysis: In contrast to the 6-8 week frequency of FOMC meeting announcements, central bankers give speeches frequently throughout inter-meeting periods, oftentimes commenting on the economic and financial conditions as well as on monetary policy considerations. We therefore create a novel series of monetary policy shocks based on central bankers' public speeches; our key innovation is to use supervised natural language modelling approaches to map speeches into implied exogenous policy shocks. These implied shocks can then be used as instruments to identify the impact of monetary policy decisions on economic outcomes, or to explore the interaction of monetary transmission with communication. The main challenge to using intermeeting communication is empirical; we need to map speeches, which are text documents, into implied policy signals.

Motivation - economic modelling approach: Our empirical strategy loosely extends on the seminal work of the monetary policy shock series by Romer and Romer (2004), who use the residual of a regression of the change in the Fed Funds Rate in each FOMC meeting on forecasts of future economic conditions as measured by the Greenbooks. The Greenbooks do not only contain numerical forecasts, as used by Romer and Romer, they also contain extensive text sections explaining and describing the respective forecasting exercises. We pair the Greenbook text sections with their respective numerical forecasts - focusing on three key dimensions: GDP, inflation (CPI) and unemployment. Using supervised text representation learning that jointly considers both text features as well as numerical features, we obtain text representations that map from Greenbook language to forecasts. This is where our setup substantially differs from the Romer and Romer approach or from a pure prediction exercise. We try to learn domain specific text features that have strong explanatory power over the target variables (the Greenbook forecasts), whilst controlling for the influence of other numerical covariates. The assumption here is that if there is any economic meaning captured in those text representations, they should be transferable to other related datasets. In our case, this would be the central bank speeches, for which we have the speeches' text but obviously no forecast figures, as their next update will only be disclosed at the next FOMC meeting. For each speech, we can then estimate a) the implied monetary policy signal on changes in GDP, CPI and unemployment forecasts and b) establish a measurement for the information dispersion across central bank speeches, which is an interesting economic measure in itself when it comes to assessing the effectiveness of central bank communication and guidance and its effect on market expectations.

Motivation - topic modelling approach: To construct the mapping from central bank texts to forecasts, we use supervised learning methods in form of topic models that can incorporate both numerical covariates as well as labels (Card et al., 2018; Ahrens et al., 2021). The key reasons why we opted for a topic modelling approach to represent the text features are that such models yield a reasonably high level of interpretability whilst working reliably even in research settings with relatively "small" datasets compared to more mainstream NLP applications with millions of datapoints. Supervised topic models, such as Card et al. (2018); Ahrens et al. (2021), allow us to learn the domain specific text representation whilst controlling for other numeric covariates such as macroeconomic and financial market conditions, which also potentially affect the textual content of central bank reports. The use of generative topic models can further be motivated from the economic modelling side. Generative models are akin to structural models in economics, and provide a complete description of the joint distribution of text, covariates, and dependent variables (policy signals in our case).

Our contribution: With this paper, we aim to provide to the research community a novel, monetary policy shock series based on central bank speeches. ${ }^{1}$ We construct a monetary policy signal dispersion index along three key economic dimensions: GDP, CPI and unemployment. This shock series is not only more frequent than series that focus on FOMC meetings, it also opens up the possibility of answering new questions that have up until now been difficult to analyse. For example, do markets form different expectations when facing a "cacophony of policy voices". Our initial estimates suggest there might be evidence for it.

\footnotetext{
${ }^{1}$ available at: github.com/MaximilianAhrens/data/tree/main/ central_bank_speech_signals
} 
Finally, we further advance the empirical use of machine learning and data-science methodologies in economics.

\section{Related Work}

\subsection{Economics - Monetary Policy and Central Bank Communication}

In the introduction, we already outlined the different mainstream approaches on identifying monetary policy shocks (Romer and Romer, 2004; Gürkaynak et al., 2005; Gertler and Karadi, 2015; Nakamura and Steinsson, 2018; Gertler and Horvath, 2018). The monetary policy literature suggests there is evidence that central bank communication can have an impact on an array of different financial market instruments, for example see Gürkaynak et al. (2005); Boukus and Rosenberg (2006); Blinder et al. (2008); Carvalho et al. (2016). However, whilst some papers on monetary policy shocks consider the timings of central bank meetings and announcements, they tend not to look into the actual language content of the central bank communication. With the onset of more accessible natural language processing models for the wider research community, this has recently started to change. Bholat et al. (2015) introduced initial text mining and language modelling approaches for central bank communication. Shiller (2017) brought forward the notion of Narrative Economics, suggesting the importance of language-based narrative in forming public beliefs and emphasizing more systematic incorporation of information conveyed through language into economic modelling. For monetary policy in particular, Haldane and $\mathrm{McMa}-$ hon (2018) outline the importance of central banks' roles in shaping public narrative on economic conditions and uncertainties. Hansen and McMahon (2016) use dictionary methods and topic models analysing the content of central banks' forward guidance and find that it has larger effects on financial markets than announced views of current economic conditions. Ahrens (2018) extends the Romer and Romer (2004) shock series with topic features based on FED Beigebook to extract a more exogenously driven monetary policy shock series that reconciles recent empirical data with monetary policy theory. Ochs (2021) builds on this text analysis framework for monetary policy shocks as well and comes to similar conclusions. Hansen et al. (2019) analyse the Bank of England's Inflation Reports via topic modelling and find that communica- tion plays an important role in shaping perceptions of uncertainty in long-run interest rates.

Some former monetary policy makers believe that monetary policy decisions hold greater weight with markets when the committee communicates a single message (Schonhardt-Bailey, 2013). The open question is how should a central bank "communicate effectively and honestly" (Blinder, 2018) when the central bank has multiple decision makers who, naturally given the complex nature and uncertainty of the decisions, often disagree. While many worry about the effects of a cacophony of voices, there is no hard evidence on the exact extent or nature of it in practice. Compared with using the policy shocks associated with the announcements, our shock series is uniquely placed to address this cacophony of voices problem. Firstly, the cacophony arises most generally through speeches and interviews (individual member communications) rather than through the statements or even minutes; while the existing literature typically ignores the signals in individual member communications, they are the focus of our analysis. Yellen (2017) suggests that one of the main disruptive effects of policymakers' public speeches is the transmission of disagreement regarding individual short-run policy goals. Our shocks capture exactly this. We can use their range and variance as a measure of cacophony.

\subsection{NLP - Modelling with Numeric and Text Data}

We use a supervised topic modelling approach that learns a domain specific text representation that is optimized to predict the target variable together with other numerical covariates.

Topic models are a popular choice when it comes to incorporating text features into, for example, social and data science models (Gentzkow et al., 2019). Many topic models have built on the seminal work by Blei et al. (2003). Supervised topic models such as (Blei and McAuliffe, 2008; Zhu et al., 2012; Chen et al., 2015) allow to infer topics that are relevant for predicting a domain specific label. Topic models such as (Eisenstein et al., 2011) and (Roberts et al., 2014) take into account the effect of numeric covariates on the topic distributions but do not explicitly use labels to guide the topic discovery process. However, recent supervised topic models such as (Card et al., 2018; Magnusson et al., 2020; Ahrens et al., 2021), have combined those previous two approaches, which allow 
for jointly learning text representations and prediction parameters based on both labels and numeric covariates. Such topic model class is the most suitable for our research setup, where our labels are the numeric forecasts in the Greenbook section, which we want to predict based on their associated text sections as well as other relevant economic and financial indicators at that time. Card et al. (2018) have proposed such model (SCHOLAR) for classification tasks. Ahrens et al. (2021) propose a Gibbs-sampled alternative to SCHOLAR, BTR, as well as a regression extension of SCHOLAR, rSCHOLAR. We use rSCHOLAR for our work. ${ }^{2}$

\section{Data}

Our empirical dataset consists of two distinct yet related data subsets - the FED's Greenbook data and the public speeches of its central bankers. The first one comprises all numerical and text data captured in the 145 Greenbooks released from 1990 to 2013. ${ }^{3}$ The Fed drafts a new Greenbook report about every 6-8 weeks in the run-up to the FOMC meetings. The Greenbook data contains numerical estimates on a multitude of contemporary economic figures as well as forecasts for several time horizons. Those numbers are accompanied by paragraphs which, for instance, put the forecasts into context and explain the rationale behind them. Different sections in the Greenbook focus on different economic and financial indicators. We use the provided separation by headlines and sections to obtain a granular mapping about which text passages pertain to which numerical figures. Our second data subset comprises textual transcripts of over 3000 speeches given by different central bank officials over the time-span from 1993-2013.

\section{Topic Model}

SCHOLAR (Card et al., 2018) is a supervised topic model that generalises both sLDA (Blei and McAuliffe, 2008) as it allows for predicting labels, and SAGE (Eisenstein et al., 2011) which handles jointly modelling covariates via 'factorising' its topic-word distributions into deviations from the background log-frequency of words and deviations based on covariates. SCHOLAR is solved via neural variational inference (Kingma and Welling, 2014; Rezende et al., 2014). However, it was not

\footnotetext{
${ }^{2}$ https://github.com/MaximilianAhrens/scholar4regression delay
}

primarily designed for regression tasks. We therefore use rSCHOLAR, an extension by Ahrens et al. (2021), which incorporates linear and non-linear regression layer options in the prediction network of the model. As we don't further modify this model, we outline the generative process here and refer to Card et al. (2018) for more details on the model:

for each document $i=1, \ldots, D$ :

1. $\boldsymbol{\zeta}_{i} \sim \mathcal{N}\left(\boldsymbol{\zeta} \mid \boldsymbol{\mu}_{0}(\alpha), \operatorname{diag}\left(\boldsymbol{\sigma}_{0}^{2}(\alpha)\right)\right)$

2. $\boldsymbol{\theta}_{i}=\operatorname{softmax}\left(\boldsymbol{\zeta}_{i}\right)$

3. $\boldsymbol{\eta}_{i}=f_{\text {gen }}\left(\boldsymbol{\theta}_{i}, \boldsymbol{c}_{i}\right)$

4. for each word $n=1, \ldots, N_{d}$ in document $i$ :

(a) $w_{i, n} \sim \operatorname{Multi}\left(w \mid \operatorname{softmax}\left(\boldsymbol{\eta}_{i}\right)\right)$

5. $\boldsymbol{y}_{i} \sim p\left(\boldsymbol{y} \mid f_{y}\left(\boldsymbol{\theta}_{i}, \boldsymbol{c}_{i}\right)\right)$

where $\zeta$ is the reparametrisation variable (Kingma and Welling, 2014), and $\boldsymbol{\mu}$ and $\boldsymbol{\sigma}^{2}$ are the mean and diagonal-variance parameters of the logistic normal prior for document-topic distribution $\boldsymbol{\theta}$ (Srivastava and Sutton, 2017). $\alpha$ is a Dirichlet hyperparameter for $\zeta . \eta$ are the topic assignments, $c$ are the numeric covariates, $w$ the words and $\boldsymbol{y}$ the label (or target variable). $f_{\text {gen }}$ is a neural network for the generative topic modelling part. $f_{y}$ is the prediction layer part of the model, which can be chosen to be virtually any form of adequate neural network structure. In our case, we focus on i) the special case where it is just a linear regression and ii) when topics and covariates are allowed to interact with each other through feed-forward layers. Regression network $f_{y}$ and generative network $f_{\text {gen }}$ are jointly optimized via backpropagation using Adam (Kingma and $\mathrm{Ba}, 2015$ ).

\section{Economic NLP Model}

As described earlier, the model estimation process is broken down into two stages: 1) learning the mapping from central bank language to economic conditions, 2) applying the learned mapping to central bank speeches. This section will outline the estimation equations at each stage and for the three economic signals: GDP, CPI, and unemployment.

\subsection{Stage 1 - Learn Mapping from Central Bank Language to Economic Conditions}

In the first stage, we learn text representations that map from the FED's Greenbook texts to its forecasts. We categorize the Greenbook sections according to which forecast they pertain to. Subsequently, we estimate a separate mapping equation for each of the three distinct economic signals. For each of these equations respectively, the left hand 
side is the FED's Greenbook forecast for GDP, CPI or unemployment over the next year. We control for both the latest contemporary values of GDP, CPI and unemployment as well as the forecast values in the previous Greenbook report. The respective Greenbook text sections serve as the text features for which we want to learn their association with the corresponding Greenbook forecasts, controlling for the influence of the numeric covariates.

As an example, we show below the mapping equation for CPI, where the target variable is denoted as $\Delta \phi_{4: 0, m}$. It represents the change in the CPI forecast $\pi$ over the next year at FOMC meeting timestamp $m$. The target variable for GDP is $\Delta g_{4: 0, m}$ and $\Delta u_{4: 0, m}$ for unemployment. Otherwise, the equations for GDP and unemployment have the same RHS variables except that the text corpus is each time specific for the respective Greenbook forecast section, i.e. $\theta_{\pi}$ represents the topic mixtures for the CPI corpus. Similarly we have $\theta_{g}$ for GDP and $\theta_{u}$ for unemployment. $\theta_{\{\pi, g, u\}, k}$ represents the $k^{t h}$ topic feature for the respective corpus. In the linear case, we can write out the entire explicit regression equation for $\boldsymbol{y}_{i} \sim p\left(\boldsymbol{y} \mid f_{y}\left(\boldsymbol{\theta}_{i}, \boldsymbol{c}_{i}\right)\right)$ from above quite easily as

$$
\begin{aligned}
& \Delta \phi_{4: 0, m}=\rho_{u} u_{0, m-1}+\rho_{\pi} \pi_{0, m-1}+\rho_{g} g_{0, m-1} \\
& +\rho_{\Delta u} \Delta u_{4: 0, m-1}+\rho_{\Delta \pi} \Delta \pi_{4: 0, m-1} \\
& +\rho_{\Delta g} \Delta g_{4: 0, m-1}+\sum_{k=1}^{K} \omega_{k} \theta_{\phi, k}+\epsilon_{m} .
\end{aligned}
$$

The $\rho$ s and $\omega$ s represent the regression weights and $\epsilon$ is the measurement error. If we thought in the spirit of the narrative approach in Romer and Romer (2004), we could now divide the RHS of this equation into two economically meaningful parts - the 'policy preference' component and the 'policy shock' component. The regression parameters $\omega$ serve as the policy mapping from numerical $(u, \pi, g)$ and text $(\boldsymbol{\theta})$ data features to the related central bank forecast. They represent the estimated 'policy preference' function of the equation. Under the assumption that the numerical and text features cover the relevant information space for the central bank to form its forecasts, the regression residual can be seen as the part of the forecast or policy decision that cannot be explained by the information accessible to the central bankers and therefore would be considered as some sort of an exogenous monetary policy shock to an observer. Our primary focus lies on identifying the policy mapping function rather than the classical Romer and Romer policy shock component. We want to identify this mapping and then subsequently apply it to central bank speeches. Equation (1) is being estimated with rSCHOLAR, which jointly estimates the topic mixtures and regression parameters in order to best explain the target variable.

\subsection{Stage 2 - Apply Mapping to Central Bank Speeches}

In the second stage, we take the estimated mapping from stage 1 and apply it to our central bank speeches dataset. We take the estimated regression parameters from stage $1, \hat{\rho}$ and $\hat{\omega}$ as well as the estimated domain specific topic features $\hat{\boldsymbol{\theta}}$ and apply it to each speech. The numerical features will be the last Greenbook forecasts that a central banker will have had access to at a given point in time $(m-1)$, which is in line with the regression setup in equation (1). We then obtain (i) an implied monetary policy signal for the respective target variable, and (ii) a measure of signal dispersion by assessing the range of signals that central bankers convey during any inter-meeting period.

\section{Results}

The results section is divided into three main steps that build upon each other. In the first step, we assess the quality of our mapping from Greenbook texts to forecasts and the implied predictive signal for the different policy dimensions that we estimate out of sample in the speeches. In the next step, we then derive policy signal dispersion measures from those implied predictive signals. Finally, we use the calculated dispersion indices to estimate some initial market and policy transmission effects.

\subsection{Estimating Implied Signals in Speeches}

In the first stage of our model, we aim to identify meaningful text representation in the Greenbook dataset. The training has been done by splitting the Greenbook dataset into a training and a validation set. ${ }^{4}$ We trained the models for 2000 epochs, however the validation set optimum was virtually always achieved significantly earlier. The $\mathrm{K}=20$ model with interaction terms yielded the best validation set results across topic size (range 350 topics $^{5}$ ) when evaluated according to minimizing mean-squared error in the regression part and

\footnotetext{
${ }^{4}$ Training-validation randomly split $80-20$

${ }^{5}$ larger topic models $(\mathrm{K}>50)$ did not yield better MSE results and were therefore dropped from further analyses.
} 
minimizing perplexity in the topic modelling part (topic compositions shown in Appendix A, validation set performance Appendix B). Table 1 shows the training set (on Greenbook data) and test set (on speech data) predictive $R^{2}$, which is defined as $R^{2}=1-\frac{m s e(\text { data })}{v a r(\text { data })}$. It reflects the percentage of explained variance of the respective target variable. The bottom part of the table shows that the model with numeric and text features fits the Greenbook validation /training data a lot more accurately than the purely numeric baseline model. Those results might be an indicator that our NLP model learned relevant text representations. However, purely judging on the training results does not yet give us much insight into whether these results might be a mere artefact of potential overfitting. When looking at the upper half of Table 1, we get assurance that our model did not just fit noise in the training data. The supervised mapping from Greenbook language to forecasts has been applied to the speeches dataset which had not been used at all as part of the training process. The NLP model substantially outperforms the purely numeric model. It explains $66 \%$ more out-of-sample variance in the speech data for the CPI target, $10 \%$ more variance on the GDP target, and $8 \%$ more variance on the unemployment target. All results are based on mean outcomes over 50 model runs per target. Figure 1 visualizes the actual FED forecast series (blue) and the predicted forecast values based on the speech dataset.

\begin{tabular}{lrr}
\hline predictive $\mathrm{R}^{2}$ & numeric & numeric + text \\
\hline Speeches - GDP signal & 0.524 & $\mathbf{0 . 5 7 7}(\mathbf{0 . 0 1 6})$ \\
Speeches - CPI signal & 0.346 & $\mathbf{0 . 5 7 5}(\mathbf{0 . 0 3 9})$ \\
Speeches - Unempl. signal & 0.630 & $\mathbf{0 . 6 8 1}(\mathbf{0 . 0 1 9})$ \\
\hline Greenbook - GDP training & 0.502 & $\mathbf{0 . 7 6 6}(\mathbf{0 . 0 8 0})$ \\
Greenbook - CPI training & 0.295 & $\mathbf{0 . 7 9 0}(\mathbf{0 . 1 4 7})$ \\
Greenbook - Unempl. training & 0.458 & $\mathbf{0 . 6 5 7}(\mathbf{0 . 0 1 1})$ \\
\hline
\end{tabular}

Table 1: Predictive $R^{2}$. Models trained on Greenbook dataset, tested on speeches dataset. Best model in bold. Reported means across 50 model runs, standard errors in brackets. Numeric (OLS) has analytical solution.

\subsection{Estimating Speech Dispersion}

We can now construct economic signal dispersion measures, based on the estimated implied signals on future FED forecast changes on GDP, CPI and unemployment, which we derived from the speeches. For each of the three dimensions, we calculate the range of the implied signal for each inter-meeting period of the FOMC. This is sim- ply done by taking the distance between the most positive and most negative speech signal. There are further ways to refine this measure that we are currently exploring, for instance, by weighting the signal according to an author-relevance metric. The FED chairperson's speeches might intuitively carry higher weight than other FED officials' announcements. Figure 2 visualizes all inferred CPI signals across speeches of all central bankers who spoke during the period of our data sample. Equivalent dispersion figures for GDP and unemployment are in Appendix C. Intuitively, higher dispersion in the signal conveyed by central bank officials could be perceived as a less united policy stance and therefore a higher degree of uncertainty about future policy guidance and decision making. In a next step, we compare our policy signal dispersion measures against two common market and policy uncertainty measures - the VIX and the Economic Policy Uncertainty (Baker et al., 2016) (EPU) index. Figure 3 shows how these indices compare over time. Our dispersion indices tend to increase in similar periods when also VIX and the EPU indicate higher market uncertainty. Furthermore, our dispersion measures seem to provide a more granular insight into specific monetary policy uncertainties. As an example, before and at the onset of the global financial crisis in 2007-9, there seems to have been a relatively high degree of dispersion in terms of the CPI and GDP stance. During the crisis however, the FED appears to have communicated with a much more united and aligned voice. In the aftermath of the crisis then, as some pundits feared a threat of inflationary pressures due to ultra-low interest rates, the CPI dispersion score jumps up whilst the signals for GDP and unemployment remain more united.

If we go back and look into the raw texts of the speeches at the top and bottom end of this CPI dispersion peak around end of 2008 , we find that the speech that signalled the strongest "likelihood for higher future inflation/more dovish monetary policy stance on inflation" was given on 19th of November 2008 by Donald Kohn ${ }^{6}$ who is generally considered a moderate dove in terms of monetary policy. In this speech, he quite clearly expresses his inflation policy view (full transcript of speech in Appendix D). He sums up his speech with the words:

\section{"[... ]In sum, I am not convinced that the events of the}

\footnotetext{
${ }^{6}$ Former Vice Chair of the Federal Reserve.
} 

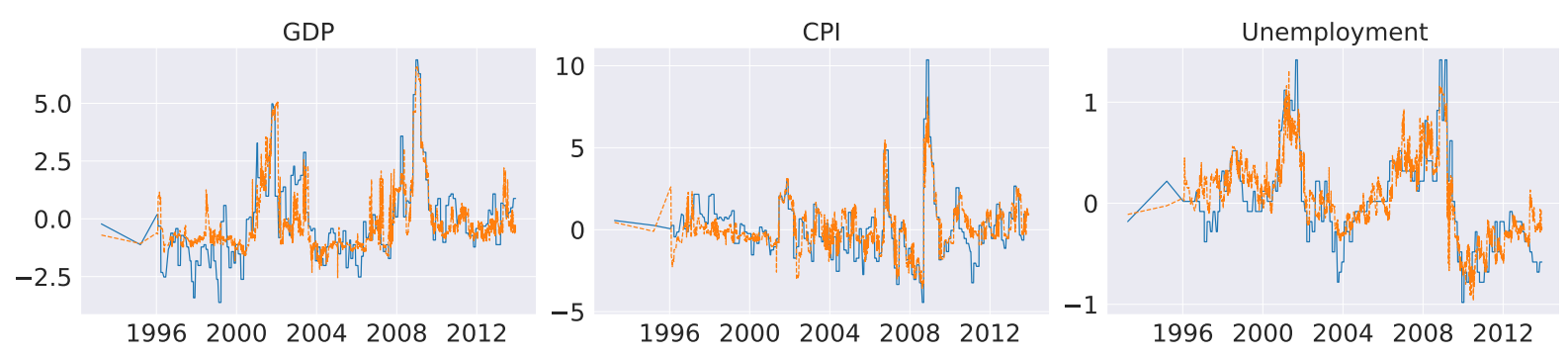

Figure 1: Out of sample implied policy signals: realised value (blue), topic model K=20 (orange)

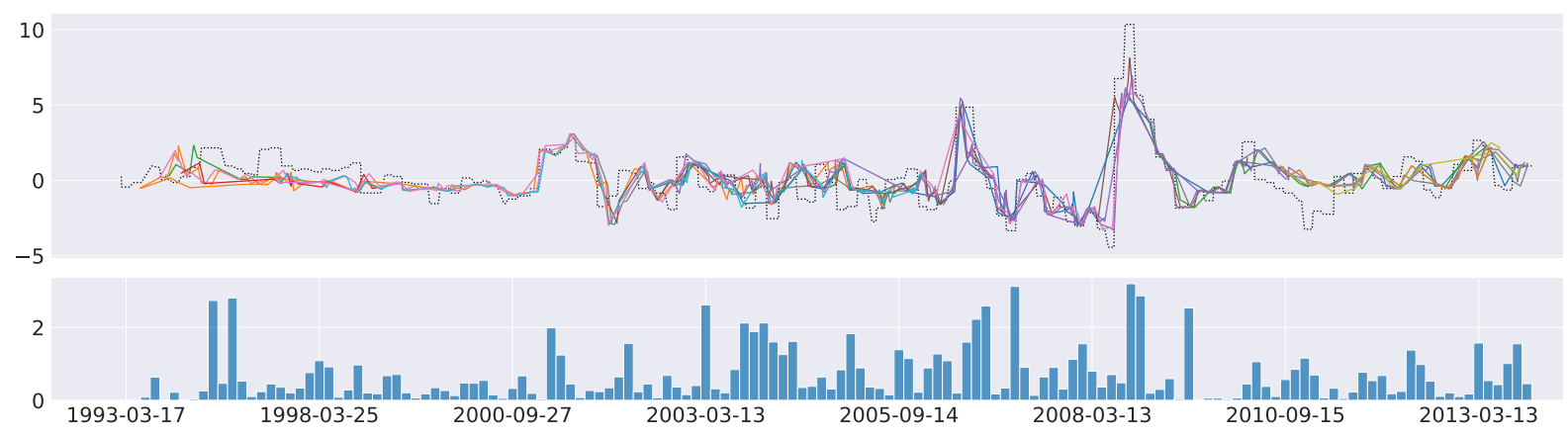

Figure 2: Out of sample estimation of monetary policy signals on CPI. Top figure: signal by individual central banker speaker. Bottom figure: derived dispersion measure (grouping window: inter-FOMC-meeting periods).

past few years and the current crisis demonstrate that central banks should switch to trying to check speculative activity through tighter monetary policy whenever they perceive a bubble forming. [...] For these reasons, the case for extra action still remains questionable, despite our having learned that the aftermath of a bubble can be far more painful than we imagined.[...]".

On the flip side, one of the speeches perceived as the most "hawkish" during the same time window was given by Jeffrey M. Lacker ${ }^{7}$, where he expressed his policy stance on inflation in his speech on 3rd of December 2008 with:

"[...] Since 2004, overall inflation has trended upward, and has been higher than I would like, over the last few years. [...]Many economists are forecasting relatively low inflation in the months ahead, on the grounds that widening economic slack is generally associated with declining price pressures. [...]I would be cautious about relying on it as a causal relationship. And while it may seem premature to be worrying about how inflation behaves after the recession is over, we need to be sure our policy remains consistent with a strategy that does not allow inflation to ratchet up over the business cycle.[...]."

\subsection{Estimating Dispersion Effects}

In order to examine the effect of FOMC members singing, or not, from the same hymn sheet, we use

\footnotetext{
${ }^{7}$ Former President, Federal Reserve Bank of Richmond
}

the three dispersion indices to create a variable indicating inter-meeting periods as characterised either by Cacophony or One Voice. There are many ways to define such an indicator but for simplicity, and to protect against outliers which would affect the standard deviation or range of the signal distribution, we use the interquartile range (IQR) for each of the GDP, CPI and unemployment series. We then average these dispersion series to get a single composite dispersion index; as an alternative, we average the two most-dispersed series, recognising that cacophony could be driven by different signals on only a subset of the three indicators. We then define a period as one of Cacophony when the series is above the median, and One Voice when below.

Figure 4 plots the Kernel Density of market surprises at the FOMC policy announcement after the inter-meeting period in which the speeches are measured. These market surprises are calculated using a narrow, 30-minute window around the FOMC announcement and, therefore, should reflect all market information priced into asset prices right before the meeting. The left figure is constructed using the average of all three signal series, and the right figure is based on the series using the two most dispersed signal series each period. Our estimates suggest that the periods in the run-up to FOMC meetings that carried a higher degree of 


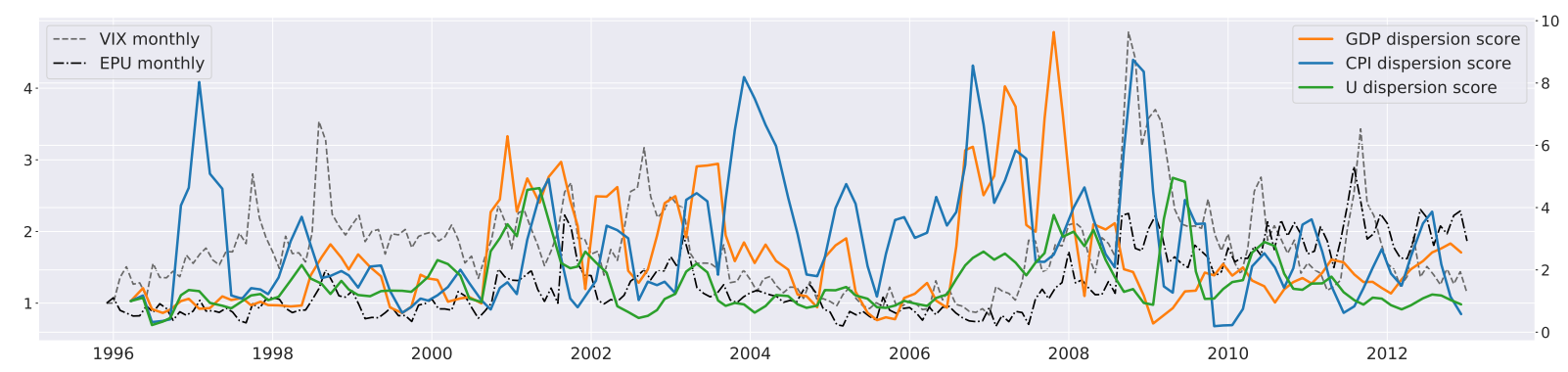

Figure 3: Dispersion scores for GDP, CPI and unemployment compared to VIX and Economic Policy Uncertainty (EPU) index. All indices re-indexed to beginning of displayed time-series.
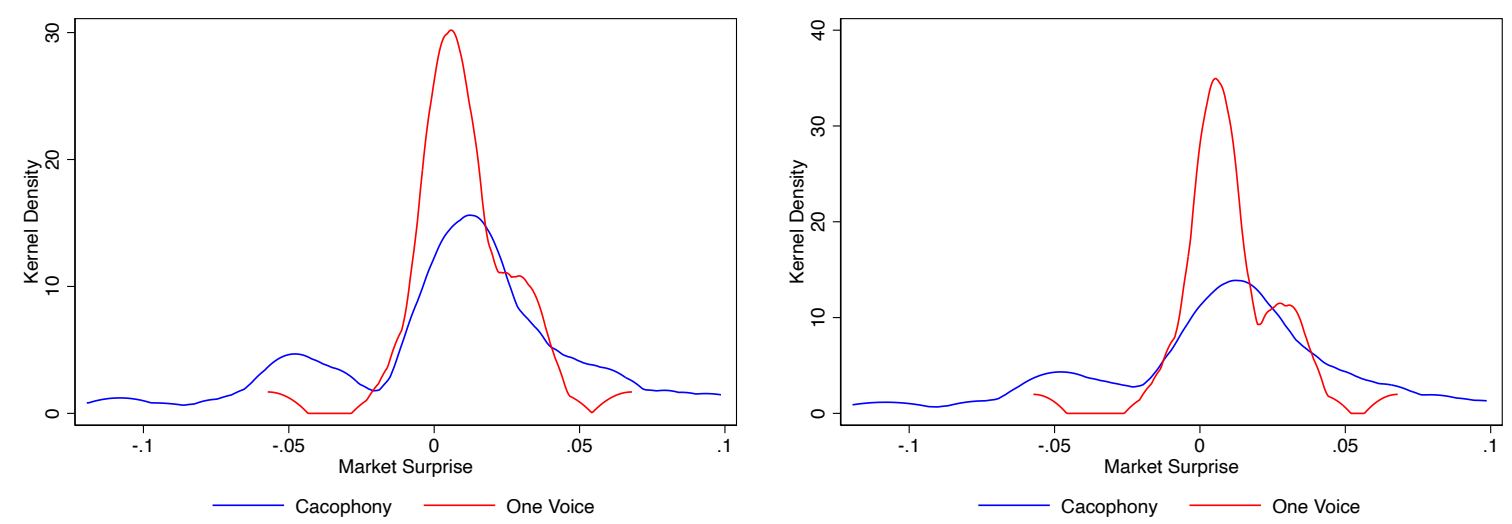

Figure 4: Kernel Density of Market Surprises when preceded by Cacophony (blue) and One Voice (red) for two different measures of the Cacophony Indicator - the left figure shows a measure based on above median values of the average of all three signal series and the right figure looks at just the two most dispersed signal series each period.

cacophony, are associated with larger market surprises at FOMC announcement time.

More formally, we run a simple OLS specification to see if our dispersion series can predict the market news. The specification involves regressing the absolute value of the market surprise on a number of controls, including an NBER recession indicator, the count of the number of speeches, as well as measures of market volatility (VIX) and uncertainty (BBD). The average signal for each indicator is also included. Table 2 reports the main findings using our two composite dispersion indices described above.

Cacophonous periods predict market surprises even when controlling for economic conditions, suggesting that our policy dispersion signals capture an important dimension of central bank communication.

\section{Further Work}

Further work on language modelling: We are currently extending our research work on the language modelling part to cover a larger range of NLP

\begin{tabular}{lccc}
\hline & $(1)$ & $(2)$ & $(3)$ \\
Regressors & Mkt News & Mkt News & Mkt News \\
\hline \multirow{2}{*}{ Lagged Dispersion Index } & & $0.019^{* * *}$ & \\
& & {$[0.002]$} & \\
Lagged Dispersion Index (alt) & & & $0.014^{* * * *}$ \\
& & & {$[0.004]$} \\
Controls & YES & YES & YES \\
& & & \\
\hline R-squared & 0.180 & 0.262 & 0.261 \\
\hline \hline
\end{tabular}

Table 2: Estimates of the effect of Cacophony on subsequent market surprise (Mkt News). Higher dispersion index implies more cacophony.

methods. This includes simpler sentiment analyses and word regressions as well as more complex fine-tuned general language models. By doing so, we aim to further refine and strengthen the central bank language mapping results.

Further work on prediction: Our current analysis focuses primarily on an approach driven by monetary economic theory modelling and interpretability in light of policy communication. We are currently extending our work into additional more prediction-focused applications such as mar- 
ket news analyses. For such exercises, we not only strictly divide the training and test by informational source but ensure that speeches in the test set do not predate Greenbooks in the training set, to counteract risks of information leakage. We will apply this approach across all applications in further versions of this work.

\section{Conclusion}

With our paper, we aim to provide to the research community a novel, monetary policy shock series based on central bank speeches. Based on a supervised topic modelling approach, we construct a monetary policy signal dispersion index along three key economic dimensions: GDP, CPI and unemployment. This "dispersion shock" series is not only more frequent than series that focus purely on FOMC meetings, it also opens up the possibility of answering new questions that have up until now been difficult to analyse. For example, is monetary policy communication more effective when communicated with "one united voice" to the markets and likewise do markets form different expectations when facing a "cacophony of policy voices". Our initial findings point towards the fact that more "cacophonous" policy communication in the buildup to FOMC meetings might be associated with stronger subsequent market surprises at FOMC policy announcement time. With our work, we hope to encourage and facilitate further research in this area.

\section{Acknowledgements}

Maximilian Ahrens is grateful for support by the Economic and Social Research Council of the UK (grant number ES/P000649/1) and the Oxford-ManInstitute. McMahon gratefully acknowledges financial support from the European Research Council (Consolidator Grant Agreement 819131).

\section{References}

Maximilian Ahrens. 2018. Natural language processing and monetary policy. MPhil Thesis, Oxford University.

Maximilian Ahrens, Julian Ashwin, Jan-Peter Calliess, and $\mathrm{Vu}$ Nguyen. 2021. Bayesian topic regression for causal inference. In Proceedings of the $2021 \mathrm{Con}$ ference on Empirical Methods in Natural Language Processing (EMNLP) (forthcoming).
Scott R Baker, Nicholas Bloom, and Steven J Davis. 2016. Measuring economic policy uncertainty. The quarterly journal of economics, 131(4):1593-1636.

David Bholat, Stephen Hansen, Pedro Santos, and Cheryl Schonhardt-Bailey. 2015. Text mining for central banks. Number 33 in Handbooks. Centre for Central Banking Studies, Bank of England.

David M Blei and Jon D McAuliffe. 2008. Supervised topic models. In Advances in Neural Information Processing Systems, pages 121-128.

David M Blei, Andrew Y Ng, and Michael I Jordan. 2003. Latent dirichlet allocation. Journal of Machine Learning Research, 3(Jan):993-1022.

Alan S Blinder. 2018. Through a crystal ball darkly: The future of monetary policy communication. In AEA Papers and Proceedings, volume 108, pages 567-71.

Alan S. Blinder, Michael Ehrmann, Marcel Fratzscher, Jakob De Haan, and David-Jan Jansen. 2008. Central Bank Communication and Monetary Policy: A Survey of Theory and Evidence. Journal of Economic Literature, American Economic Association, 46(4):910-45.

Ellyn Boukus and Joshua Rosenberg. 2006. The information content of FOMC minutes. Technical report, Federal Reserve Bank of New York.

Dallas Card, Chenhao Tan, and Noah A. Smith. 2018. Neural models for documents with metadata. In Proceedings of the 56th Annual Meeting of the Association for Computational Linguistics (Volume 1: Long Papers), pages 2031-2040. Association for Computational Linguistics.

Carlos Carvalho, Eric Hsu, and Fernanda Nechio. 2016. Measuring the effect of the zero lower bound on monetary policy. Working Paper Series 2016-6, Federal Reserve Bank of San Francisco.

Jianshu Chen, Ji He, Yelong Shen, Lin Xiao, Xiaodong He, Jianfeng Gao, Xinying Song, and Li Deng. 2015. End-to-end learning of lda by mirror-descent back propagation over a deep architecture. In Advances in Neural Information Processing Systems, volume 28. Curran Associates, Inc.

Lawrence J. Christiano, Martin Eichenbaum, and Charles L. Evans. 2005. Nominal Rigidities and the Dynamic Effects of a Shock to Monetary Policy. Journal of Political Economy, 113(1):1-45.

Jacob Eisenstein, Amr Ahmed, and Eric P Xing. 2011. Sparse additive generative models of text. In Proceedings of the 28th international conference on machine learning (ICML-11), pages 1041-1048. Citeseer.

Matthew Gentzkow, Bryan Kelly, and Matt Taddy. 2019. Text as data. Journal of Economic Literature, 57(3):535-74. 
Mark Gertler and Peter Karadi. 2015. Monetary policy surprises, credit costs, and economic activity. American Economic Journal: Macroeconomics, 7(1):4476.

Pavel Gertler and Roman Horvath. 2018. Central bank communication and financial markets: New highfrequency evidence. Journal of Financial Stability, 36(C):336-345.

Refet S Gürkaynak, Brian Sack, and Eric Swanson. 2005. Do Actions Speak Louder Than Words? The Response of Asset Prices to Monetary Policy Actions and Statements. International Journal of Central Banking, 1(1).

Andrew Haldane and Michael McMahon. 2018. Central bank communications and the general public. In AEA papers and proceedings, volume 108, pages 578-83.

Stephen Hansen and Michael McMahon. 2016. Shocking language: Understanding the macroeconomic effects of central bank communication. Journal of International Economics, 99:S114-S133.

Stephen Hansen, Michael McMahon, and Matthew Tong. 2019. The long-run information effect of central bank communication. Journal of Monetary Economics, 108:185-202.

Diederik P. Kingma and Jimmy Ba. 2015. Adam: A method for stochastic optimization. In $3 \mathrm{rd}$ International Conference on Learning Representations, ICLR 2015, San Diego, CA, USA, May 7-9, 2015, Conference Track Proceedings.

Diederik P. Kingma and Max Welling. 2014. Autoencoding variational bayes. In 2nd International Conference on Learning Representations, ICLR 2014, Banff, AB, Canada, April 14-16, 2014, Conference Track Proceedings.

Måns Magnusson, Leif Jonsson, and Mattias Villani. 2020. Dolda: a regularized supervised topic model for high-dimensional multi-class regression. Computational Statistics, 35(1):175-201.

Emi Nakamura and Jón Steinsson. 2018. Highfrequency identification of monetary non-neutrality: the information effect. The Quarterly Journal of Economics, 133(3):1283-1330.

A. C.R. Ochs. 2021. A New Monetary Policy Shock with Text Analysis. Cambridge working papers in economics, Faculty of Economics, University of Cambridge.

Valerie A. Ramey. 2016. Macroeconomic Shocks and Their Propagation, volume 2 of Handbook of Macroeconomics, pages 71-162. Elsevier.

Danilo Jimenez Rezende, Shakir Mohamed, and Daan Wierstra. 2014. Stochastic backpropagation and approximate inference in deep generative models. In Proceedings of the 31st International Conference on
Machine Learning, volume 32 of Proceedings of Machine Learning Research, pages 1278-1286, Bejing, China. PMLR.

Margaret E Roberts, Brandon M Stewart, Dustin Tingley, Christopher Lucas, Jetson Leder-Luis, Shana Kushner Gadarian, Bethany Albertson, and David G Rand. 2014. Structural topic models for open-ended survey responses. American Journal of Political Science, 58(4):1064-1082.

Christina D. Romer and David H. Romer. 2004. A new measure of monetary shocks: Derivation and implications. American Economic Review, 94(4):10551084.

Cheryl Schonhardt-Bailey. 2013. Deliberating Monetary Policy. MIT Press, Cambridge.

Robert J. Shiller. 2017. Narrative Economics. American Economic Review, 107(4):967-1004.

Akash Srivastava and Charles Sutton. 2017. Autoencoding variational inference for topic models. arXiv preprint arXiv:1703.01488.

Janet Yellen. 2017. Remarks at central bank communications conference, ecb, 14 november 2017. https://www. youtube.com/watch? $\mathrm{v}=\mathrm{DI} 7 \mathrm{p}-\mathrm{g} 5108 \mathrm{~g}$.

Jun Zhu, Amr Ahmed, and Eric P Xing. 2012. Medlda: maximum margin supervised topic models. Journal of Machine Learning Research, 13(Aug):22372278. 


\section{A Appendix - Topic Compositions}

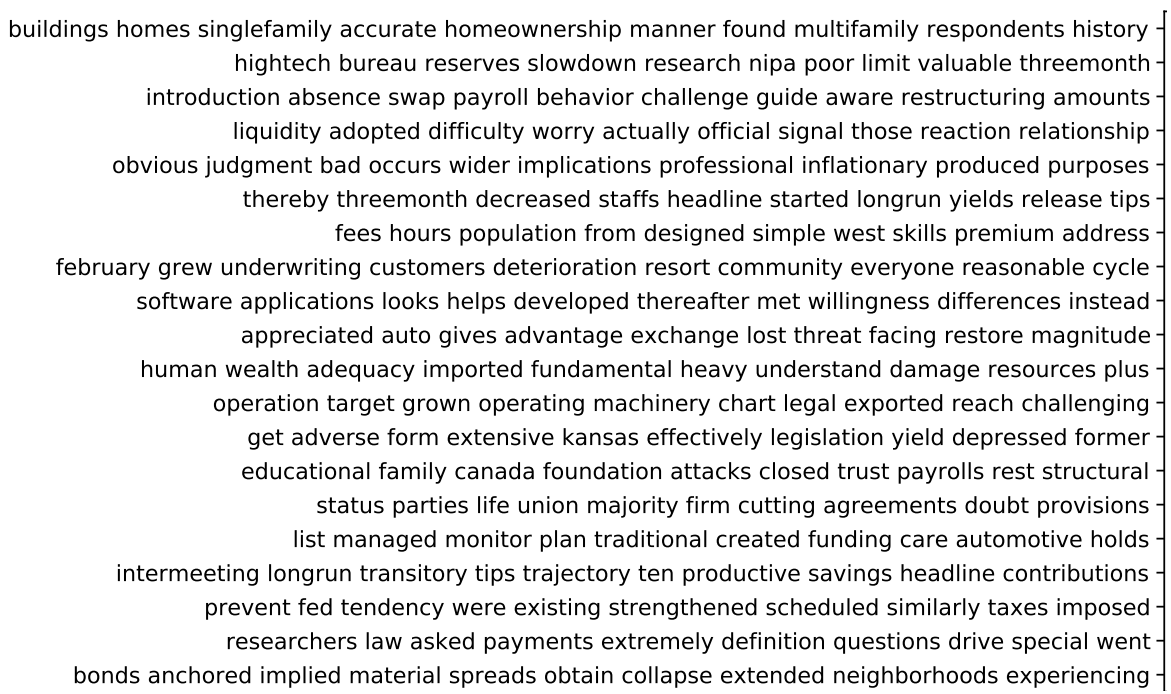

Figure 5: Top words for CPI model with interaction terms between topics and numerical covariates $(K=20)$

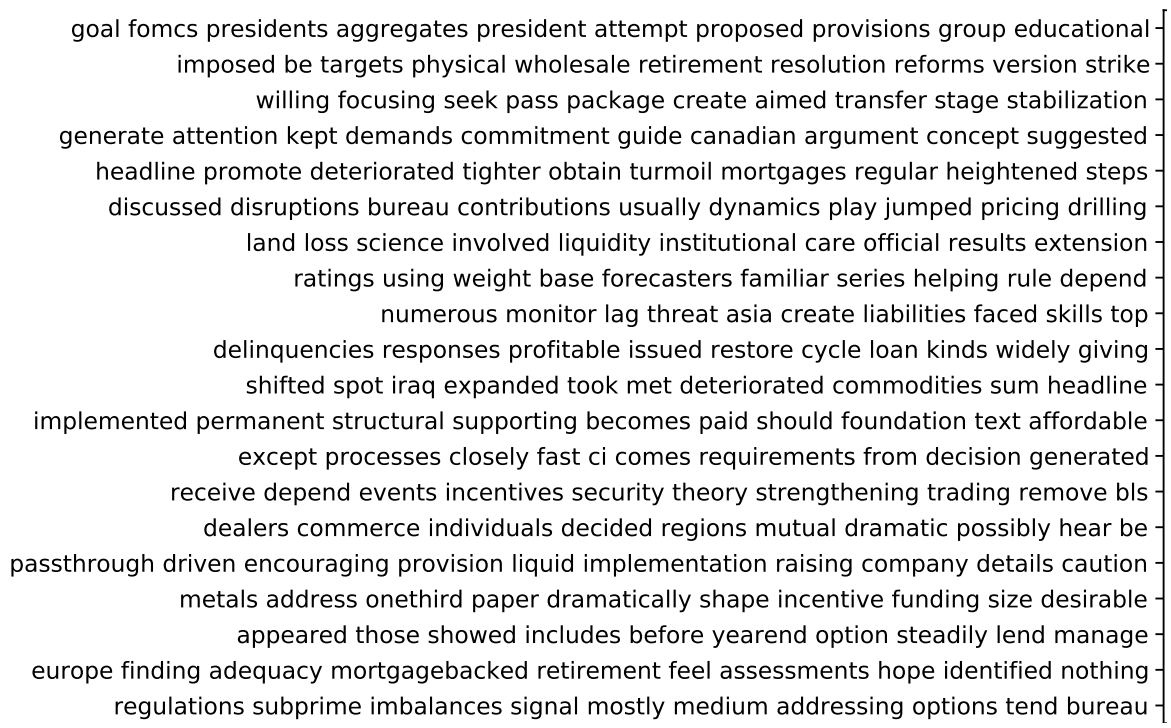

Figure 6: Top words for GDP model with interaction terms between topics and numerical covariates $(K=20)$ 


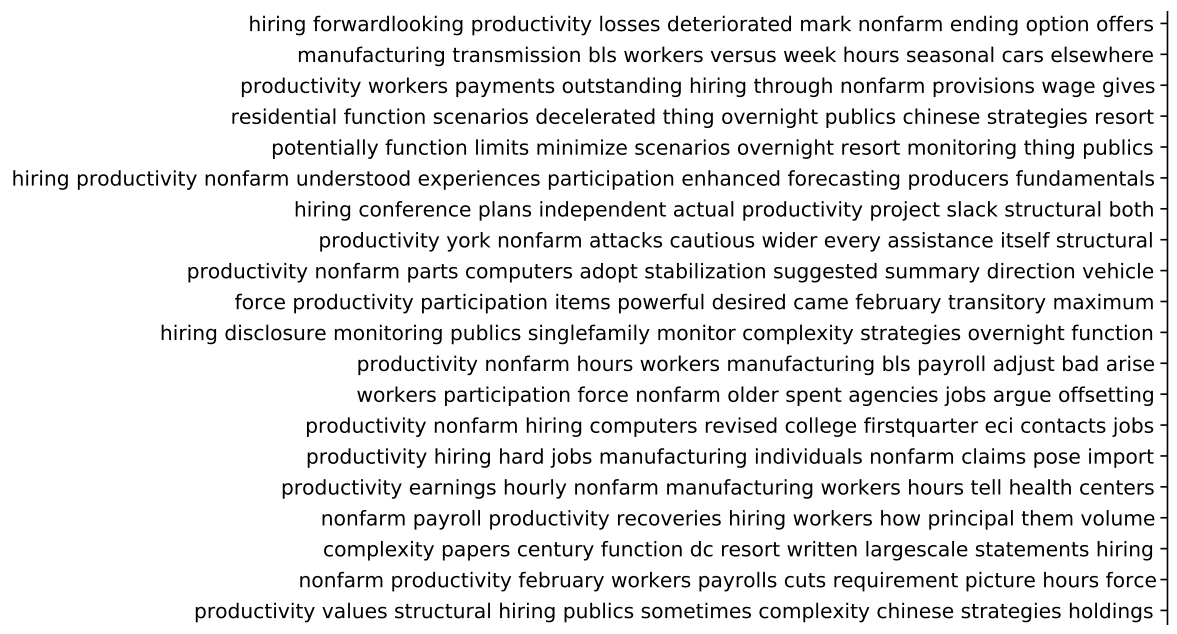

Figure 7: Top words for Unemployment model with interaction terms between topics and numerical covariates $(\mathrm{K}=20)$

\section{B Appendix - Validation set performance}

Exemplary validation set performances for model estimation runs on targets: (1) GDP, (2) CPI, and (3) unemployment. MSE and perplexity reported. Optimal parameters correspond to epoch that yielded lowest validation set MSE. Max. epochs $=2000$.
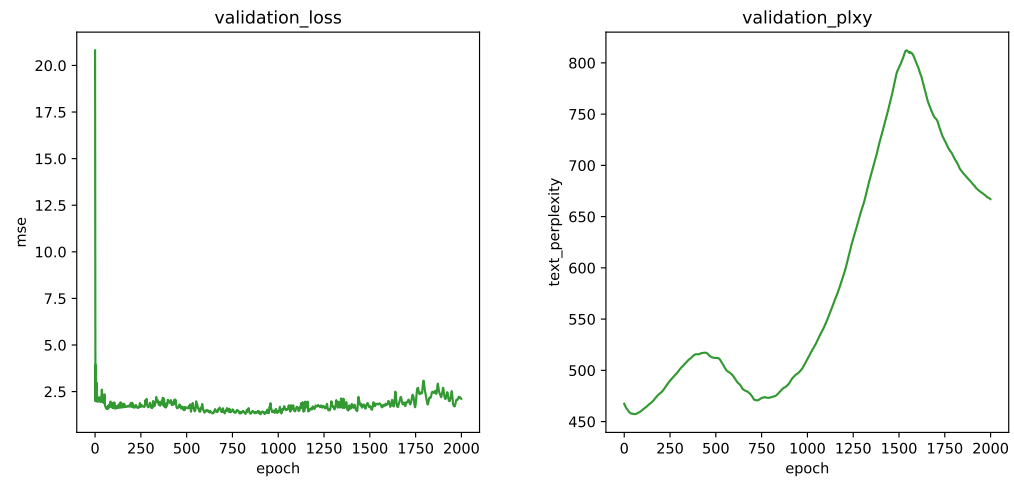

Figure 8: GDP 

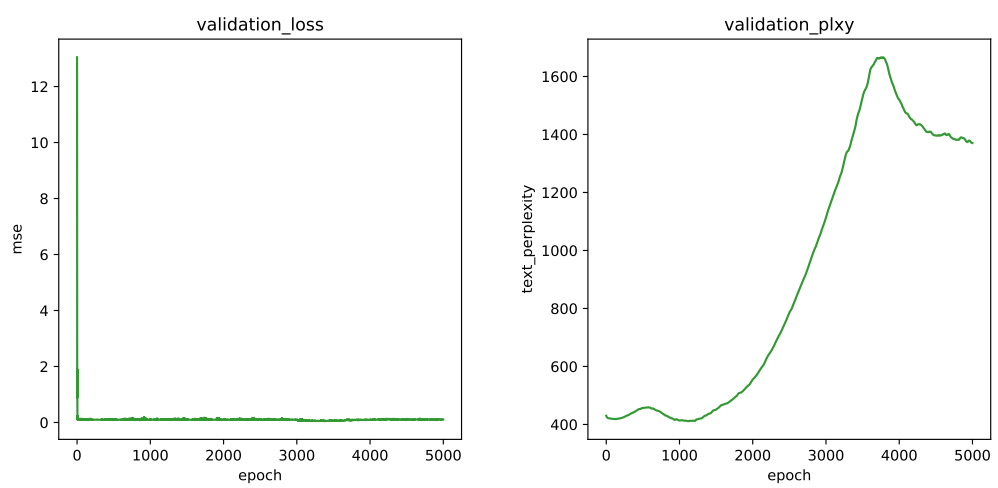

Figure 9: GDP
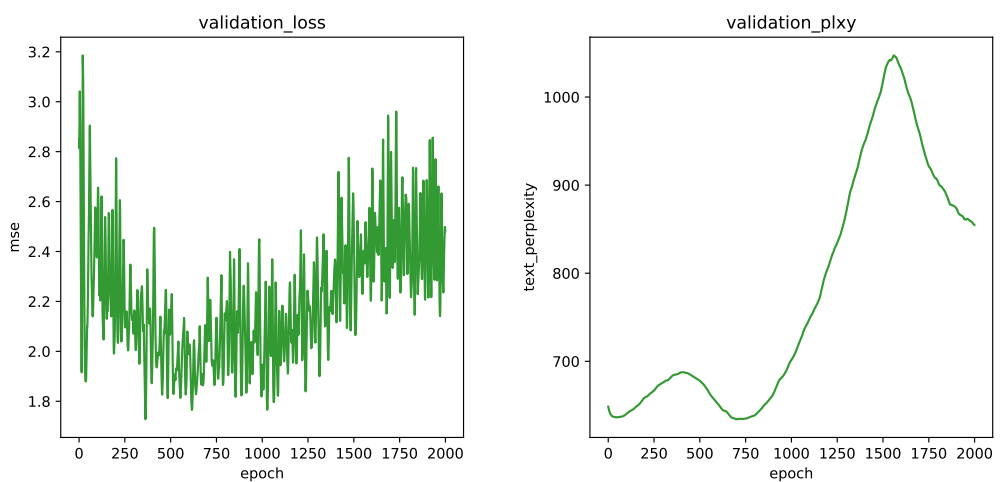

Figure 10: GDP

\section{Appendix - Implied Signal Dispersions}

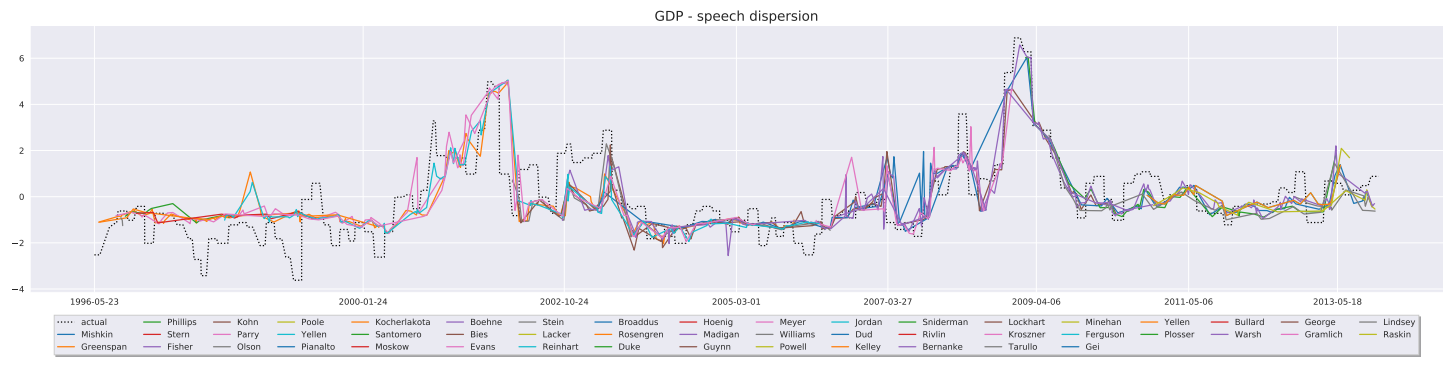

Figure 11: GDP speech signal by central banker 


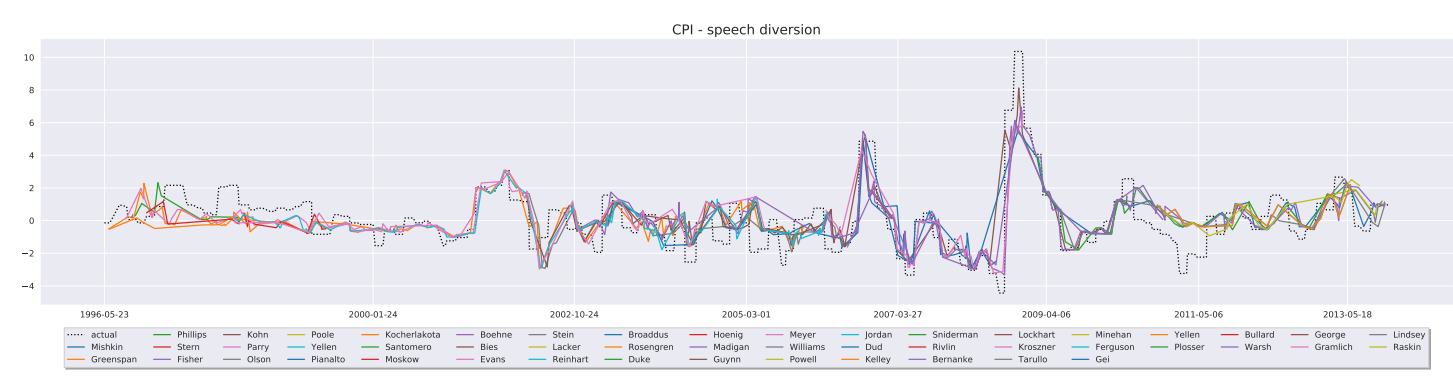

Figure 12: CPI speech signal by central banker

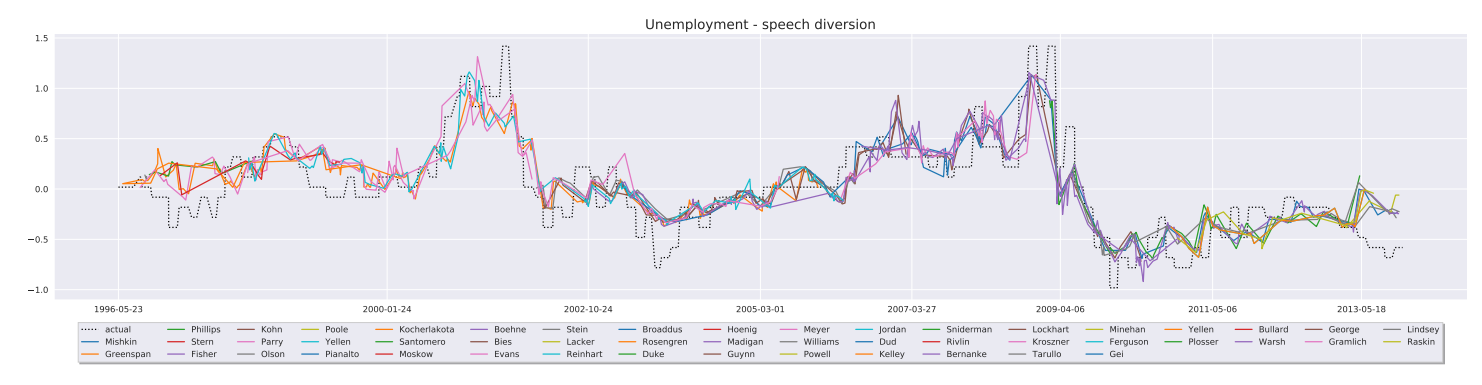

Figure 13: Unemployment speech signal by central banker

\section{Appendix - Central Bank Speech Examples}

\section{Speech by Donald Kohn, 19th of November 2008. Estimated as indicating a very dovish stance on CPI,given all other economic indicators at that time:}

Vice Chairman Donald L. Kohn At the Cato Institute's 26th Annual Monetary Policy Conference, Washington, D.C. November 19, 2008 Monetary Policy and Asset Prices Revisited As you know, we are in the midst of a global financial crisis that is now weighing heavily on economies around the world. Although the outlook remains extremely uncertain, both the fragility of the financial system and the weakness in real activity seem likely to persist for a while. To promote maximum sustainable economic growth and price stability, the Federal Reserve has responded to this crisis by easing monetary policy markedly, and we have greatly expanded our liquidity facilities to keep credit flowing when private lenders have become reluctant or unable to do so. Other central banks have also cut policy rates significantly and expanded their lending. In addition, the federal government and governments around the world have taken extraordinary actions to strengthen financial systems to preserve the ability of households and businesses to borrow and spend. 1 The current situation is so severe that it calls for careful review of how such a crisis evolved and how we can prevent a similar situation from happening again. This conference is a welcome step in that review, as it asks about the lessons we have learned, particularly for monetary policy, from the collapse of subprime lending and the preceding house-price bubble-developments that contributed importantly to the present financial crisis. This morning I would like to reflect on some of what I, in my role as a monetary policy maker, have learned from recent developments in the housing sector and, more broadly, in financial markets as a whole. In doing so, I will revisit the remarks I made in 2006 in Frankfurt at a festschrift for Otmar Issing. 2 There I argued that a central bank facing a possible asset bubble would have to surmount some high hurdles before it would be justified in tightening policy beyond what the outlook for output and inflation would require, after taking into account past and projected asset price developments. In the aftermath of the collapse of the housing market and in the midst of the ensuing financial and economic turmoil, does that conclusion still hold? More time and study will be needed before we can be confident about the lessons of the current crisis. But to foreshadow the remainder of these remarks, based on what we know today, I still have serious questions about whether trying to use monetary policy to check speculative activity on a regular, systematic basis would yield benefits that outweigh its costs. I hasten to add that it is evident from the current crisis that much has to change on the regulatory 


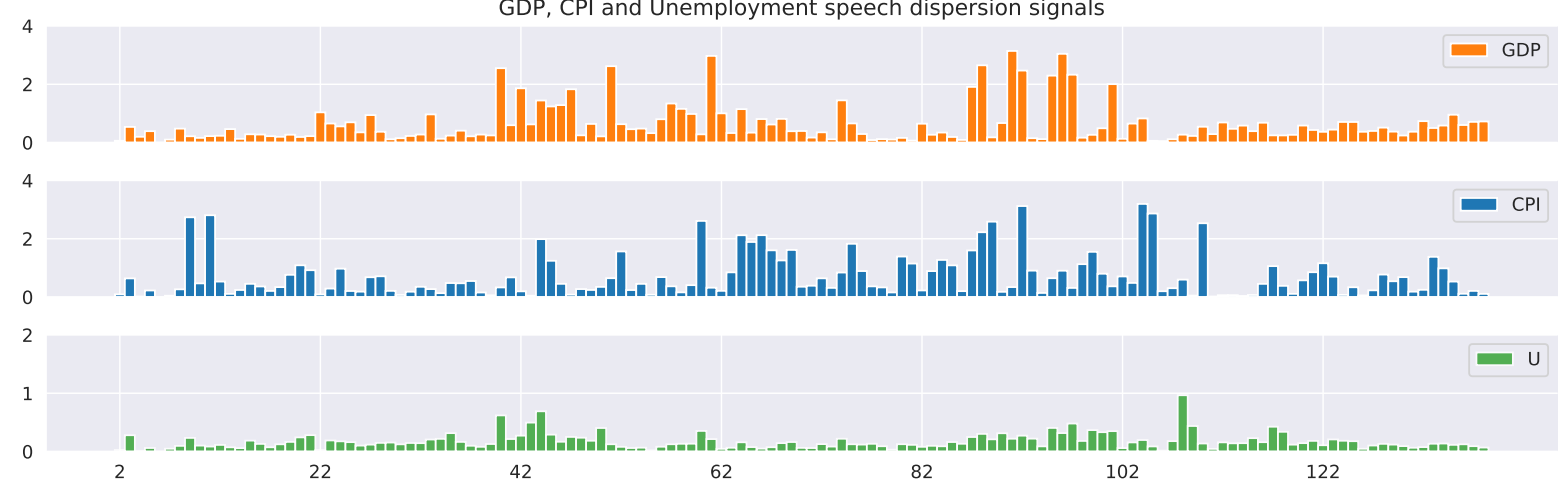

Figure 14: Signal dispersion across speakers (grouping window: inter-FOMC-meeting periods)

front. Governments around the world face the challenge of revamping the regulatory structure governing financial markets. And changes in this area, I believe, will prove to be the most necessary and effective at reducing the odds on another severe financial crisis. Today, however, I will focus on some of the lessons of the current crisis for monetary policy. Alternative Strategies for Addressing Asset Price Bubbles In my 2006 speech, I discussed two different strategies for monetary policy to deal with a possible asset price bubble-the "conventional strategy" and "extra action." A central bank following the conventional strategy does not attempt to use monetary policy to influence the speculative component of asset prices, on the assumption that it has little ability to do so and that any attempt will only result in sub-optimal economic performance in the medium run. Instead, the central bank responds to asset price movements, whether driven by fundamentals or not, only to the degree that those movements have implications for future output and inflation. This conventional strategy conforms to the Federal Reserve's dual mandate under the law and it has been our policy strategy; it also has been consistent with the practices of most inflation-targeting central banks. However, some observers have argued for a more activist policy than this one. Specifically, they have urged central banks, upon perceiving the development of an asset bubble, to take extra action by tightening policy beyond what the conventional strategy would suggest, with the hope of limiting the size of the bubble and thus the fallout from its deflation. Such a strategy, if successful, could deliver substantial benefits, and a number of central bankers have talked about the need to consider a policy of extra action on occasion, and perhaps have even implemented such a strategy. However, taking extra action also would entail some costs, such as creating, for a time, higher unemployment and lower inflation than would otherwise be desired. In assessing these two alternatives for monetary policy, in the 2006 speech I concluded that a strategy of extra action might be justified if three tough conditions were met. First, policymakers must be able to identify bubbles in a timely fashion with reasonable confidence. Second, a somewhat tighter monetary policy must have a high probability that it will help to check at least some of the speculative activity. And third, the expected improvement in future economic performance that would result from the curtailment of the bubble must be sufficiently great. Of course, we live in an uncertain world, and accordingly policymakers should always be open to the possibility that these conditions might be satisfied and that extra action would be appropriate. But my thought at the time was that, in practice, the likelihood of ever meeting the three conditions seemed remote. In the aftermath of the bursting of the housing bubble, however, the severity of the fallout might seem to call this judgment into question. So let's re-examine each of the three conditions and see what the current crisis has taught us. Potential Gain from Limiting Bubbles Let me start with my third condition, the potential gain from limiting bubbles, because this is where my views have changed the most. Although I was concerned about the potential fallout from a collapse of the housing market, I think it is fair to say that these costs have turned out to be much greater than I and many other observers imagined. In particular, I and other observers underestimated the potential for house prices to decline substantially, the degree to which such a decline would create difficulties for homeowners, and, most important, the vulnerability of the broader financial system to these events. In retrospect, I may have been unduly comforted by the resilience of the 
U.S. economy to the collapse of the high-tech bubble, to the earlier Russian debt default and failure of Long-Term Capital Management, and even to the commercial and residential real estate debacles of the late 1980s and early 1990s (as difficult as that recovery was). But mopping up after this asset price bubble has turned out to be much harder because of its greater magnitude, the centrality of residential housing and finance to our economy and financial system, and the surprising ways obscure and complex financial transactions have exposed banks and other financial institutions to heavy losses. In addition, financial and economic linkages across countries have made this crisis truly global in scope, affecting both developed and developing economies. As a result of all these factors, the economic disruption here and abroad is likely to be considerably more severe than in past episodes. The severe fallout may indicate a larger potential gain than I had anticipated to leaning against excess exuberance in asset markets. However, realizing that potential rests on meeting my two other conditions as well-the timely identification of the bubble, and the ability of a central bank to materially influence the trajectory of the speculative component of asset prices. Identifying Bubbles in a Timely Manner As for the first of the three conditions, events of the past few years, coupled with advances in our understanding of how bubbles form and persist, have made me a little less dubious that policymakers can reliably identify a serious bubble before it bursts. However, I am still skeptical about our ability to detect bubbles early enough to make a general policy of leaning against them successful on average. The identification of bubbles in real time is tricky because not all the fundamental factors driving asset prices are directly observable; thus, any judgment by a central bank that an asset is overpriced is by nature uncertain. My views on this aspect of the identification problem have been reinforced by my experience during the inflation of the housing bubble. Over the first half of the decade, we saw a sustained, rapid rise in both home values and mortgage debt. As this process continued, concern about its sustainability grew and many observers started speculating that a bubble was in place. During this period, staff throughout the Federal Reserve System examined whether house prices were overvalued and arrived at a wide range of answers. For example, one set of models that linked rental rates and house prices indicated as early as the start of 2004 that the market was significantly overvalued, while another set of models suggested, even as late as December 2005, that house prices could be justified by fundamentals. 3 Thus, controversy over the existence of a bubble persisted almost right up to the actual peak in the housing market. Because the economic consequences of mistakenly responding to a misidentified bubble are substantial, central bankers may be reluctant to take extra action in the face of such uncertainty, especially if they are risk-averse. Policymakers may also be reluctant to act because a bubble "call" might seem to require them to be more knowledgeable than market participants. After all, if at least some market participants perceive the emergence of a bubble, wouldn't they arbitrage that mispricing away? Recent research, however, suggests reasons for why market participants who think they know that a bubble exists still may not trade to eliminate it. For example, if some market participants recognize the presence of a bubble but do not know how common their knowledge is, they might reasonably expect to make the most profits by riding the bubble for as long as possible, with the goal of trying to sell the asset just before it collapses. 4 Other research emphasizes that certain institutional structures-such as secured lending and delegated portfolio management-can create substantial costs in trading against an asset price bubble, so that even market participants who are conscious of the bubble will not find it profitable to trade against it.5 Together, these studies suggest that policymakers may be able to detect bubbles that will not be quickly arbitraged away, thus strengthening the argument for considering extra action.6 Nonetheless, even if policymakers are confident that a bubble has emerged, the question of the timeliness of the call remains. The essential problem is the timing of the detection of the bubble relative to the timing of its collapse. The risk is that the detection and subsequent policy response occur not long before the bubble collapses on its own. Given the lags associated with monetary policy, the resulting contractionary effects on the economy of the monetary tightening would occur just when the adverse effects of the bubble's collapse are being realized, worsening rather than mitigating the effects of the bubble's collapse. And the inevitable lags in detecting bubbles increase the likelihood that, by the time action is taken, speculative activity will have progressed to the point that its collapse is not far off. Thus, even if we could have known for sure that a housing bubble existed, and that tighter monetary policy would have significantly checked the unwarranted rise in home prices, policymakers would have had to make 
this call early on-at least a year and probably more before the peak in the real estate market in 2006-for such an action to have been beneficial. Ability of Monetary Policy to Influence Bubbles This brings me to the remaining condition-the requirement that monetary policy be able to materially check expansions in asset bubbles. Clearly, interest rates play an important role in determining the fundamental value of corporate equity, houses, and other assets. However, I noted in my earlier speech that the influence of interest rates on the speculative component of asset prices is unclear from both a theoretical and empirical standpoint. My views on this issue have not changed much, largely because of the still-murky role that monetary policy played in promoting the surge in house prices and the accompanying run-up in both conventional and subprime mortgage debt. Although tighter monetary policy might have succeeded in shifting down the path of house prices, it is still not clear to what extent small or even moderate policy actions would have discouraged the broader speculative developments that have characterized the current episode: overly optimistic expectations of price appreciation, excessive leveraging, and a marked increase in risk-taking by homeowners and investors. Of course, a substantial tightening of policy, leading to a significant slowing in the economy and rise in unemployment, might have had a marked effect on housing price gains. But undertaking such a policy course on a regular basis whenever asset price misalignments are detected would likely prove to be a relatively poor strategy on average, especially given the possibility of false positives in identifying these misalignments, and the existence of other potential remedies. In general, taking more-targeted steps-for example, regulatory changes intended to strengthen the financial system-would seem a better course of action under such circumstances. To be sure, some observers contend that the low level of the federal funds rate in 2003 and 2004 was clearly a primary cause of the housing bubble, and that a significantly tighter stance of monetary policy would have been warranted. As you know, the Federal Open Market Committee (FOMC), after having sharply lowered its policy rate during the 2001 recession, further lowered the federal funds rate in late 2002 and 2003 in response to an outlook for continued tepid real growth and a possible unwelcome disinflation. This accommodative stance helped set the stage for a more robust recovery, and as the expansion took hold in 2004, the FOMC began to tighten in a gradual manner that was publicly signaled in advance. How might these monetary policy actions have fueled speculation? Perhaps a low policy rate early in the decade, by stimulating housing demand and pushing up the level of home prices, incorrectly led households and lenders to extrapolate these price increases into the indefinite future. Overly optimistic expectations may have had an unusually stimulative effect on the housing market after 2003 because borrowing constraints were being eased by new financial developments, such as the growth of subprime lending and other nontraditional mortgages, fueled in part by investor demands for the higher yields on complex structured products.7 In addition, the increased use of adjustable-rate mortgages-which are more closely tied to short-term policy rates-may have initially boosted the stimulus from a lower federal funds rate. These stories have a certain plausibility, but a closer examination raises questions about monetary policy and the housing and credit bubbles. Although low short-term interest rates probably supported housing demand and home prices for a time-an effect that helped offset the negative effects on economic growth and employment of the steep decline in business investment-the role of monetary policy in fueling the speculation in real estate is still not clear. Studies that have tried to address how much monetary policy contributed to the increase in house prices during this period are inconclusive. 8 And in general, the channel from interest rates to house prices has not been strongly established empirically, suggesting it might take a very large hike in the federal funds rate to have a substantial effect on real estate values.9 Moreover, if accommodative monetary policy engendered extrapolative expectations and speculation starting in 2003, why did it not restrain these factors after mid-2004 as the federal funds rate was increased? Tightening should have limited the extent to which households (especially those using variable-rate mortgages) were able to borrow, thereby slowing the pace of house price appreciation. Furthermore, many of the worst subprime loans were made after the federal funds rate had normalized, and reflected a wide array of deficiencies in the financial markets. The contrasting movement of short-run and long-term interest rates over this period further complicates any assessment of the link between monetary policy and the housing market. Housing demand and home prices are, presumably, most closely linked to the 30-year fixed mortgage rate and the expected average borrowing rate to be paid over the life of adjustable-rate mortgages. That these 
actual and expected loan rates moved sideways even as the federal funds rate rose suggests that other factors besides monetary policy were at work, especially since the FOMC clearly signaled that it would be returning the funds rate to a normal level over time (albeit at a "measured pace"). A good portion of the appreciation in house prices probably is due to the structural changes that were taking place in mortgage financing-specifically, the opening up of subprime lending and the expansion in associated securitization markets with its strong demand for mortgages from investors. Gauging the effects of expanded subprime lending on house prices is complicated by two-way causality-more lending can drive up house prices, but expected house price increases can also induce more lending. Undoubtedly, causality did indeed run both directions. But studies do indicate that an expansion in credit leads to increased house prices, and suggest that structural changes in mortgage finance likely boosted the rate of house price appreciation.10 Another key observation that must be reconciled with any explanation of recent events is that the run-up and subsequent decline in house prices was not limited to the United States; indeed, some countries have experienced even larger swings in house prices.11 In most countries during this period, long-term interest rates were low despite the fact that their central banks did not ease monetary policy as markedly as the Federal Reserve. A common factor behind these low rates, and perhaps in part behind the shared increase in house prices as well, is the "global saving glut" identified by Chairman Bernanke-the large amounts of savings, both official and private, from Asian and oil-exporting nations that tended to lower neutral interest rates globally.12 In a broader sense, perhaps the underlying cause of the current crisis was complacency. With the onset of the "Great Moderation" back in the mid-1980s, households and firms in the United States and elsewhere have enjoyed a long period of reduced output volatility and low and stable inflation. These calm conditions may have led many private agents to become less prudent and to underestimate the risks associated with their actions. While we cannot be sure about the ultimate sources of the moderation, many observers believe better monetary policy here and abroad was one factor; if so, central banks may have accidentally contributed to the current crisis. But would a somewhat tighter stance of policy in recent years have reversed this complacency? It seems doubtful. Central banks would likely have needed to produce recessions of some consequence in order to force agents to reevaluate the costs of taking on risk-an outcome unlikely to improve societal welfare. Rather than using the blunt tool of monetary policy to induce prudence, we should examine more closely the possibility of using regulation and prudential supervision to address concerns about overleveraging and other risk-taking behavior. In short, we still do not fully know what caused the run-up in house prices and over-building. Short-term rates were low in 2002-04 as the Federal Reserve countered the risks it saw to good economic performance, and these low rates probably had some effect on housing markets at the time. But the problems largely built up after policy rates were well on their way to neutral, and other factors appear to have played major roles. We have learned little about the likely effect that a somewhat higher funds rate would have had on the speculative element of prices. Of course, it is important to keep an open mind about the relationship of short-term interest rates and speculative activity. If it becomes clear that monetary policy can predictably influence the evolution of bubbles, central banks should take that ability into account when crafting policies intended to keep output rising in line with its potential and inflation low and stable. Conclusion In sum, I am not convinced that the events of the past few years and the current crisis demonstrate that central banks should switch to trying to check speculative activity through tighter monetary policy whenever they perceive a bubble forming. The recent experience may have made us a bit more confident about detecting bubbles, but it has not resolved the problem of doing so in a timely manner. Nor has it shown that small-to-modest policy actions will reliably and materially damp speculation. For these reasons, the case for extra action still remains questionable, despite our having learned that the aftermath of a bubble can be far more painful than we imagined. Some may object to this assessment, arguing that the current crisis is so bad that, in retrospect, monetary policy should have been appreciably tighter to deflate or forestall the housing boom earlier in the decade, even if that meant a substantially weaker economy. This argument has two defects. First, monetary policy is made in real time, not with the benefit of hindsight, and any evaluation of competing strategies for the systematic conduct of policy must be grounded in that fact. Although we must learn from history, we cannot implement policy strategies that assume more information about the future than we can ever have. Second, even if we ignore 
the fact that policymakers at the time could not have known what the future held in store if the funds rate followed the path it actually did, we also need to recognize that we cannot be sure what would have happened if policy had taken a different course. If policy had tightened appreciably at an early stage of the housing boom, say in mid-2003, it would have done so when the unemployment rate was still rising and inflation seemed poised to move to an undesirably low level. Such a course of action might well have created its own unforeseen consequences that we might now be ruing. This assessment aside, recent events would seem to have some implications for the conduct of monetary policy. For example, in light of the demonstrated importance to the real economy of speculative booms and busts (which can take years to play out), central banks probably should always try to look out over a long horizon when evaluating the economic outlook and deliberating about the appropriate accompanying path of the policy rate. The Federal Reserve staff has for sometime regularly provided the FOMC with this sort of extended-horizon analysis. In particular, the staff regularly generates likely paths for the economy over the next five years or so under different economic and policy assumptions; these scenarios often highlight different possibilities for the evolution of prices for homes and other assets. Note that the focus here is not a single baseline outlook; rather, the emphasis is on exploring the various ways events could play out and the implications for monetary policy. Another lesson of the current crisis is that central banks need to improve their understanding of the workings of the financial system, its vulnerabilities, and its links to the real economy. We must try to find ways to discern more quickly if financial innovation and other factors are leading to a buildup of destabilizing forces, such as rapidly rising asset prices or excessive leverage. Moreover, the unexpectedly rapid resonance of financial turmoil through global markets signals a need for further study of the complex cross-country linkages among lenders and borrowers, and the ways in which those linkages are influenced by such factors as leverage, interdependent counterparty relationships, and backup liquidity agreements. Finally, more effort needs to be spent on further investigation of the financial accelerator and other credit-channel effects, given the accumulating evidence that such effects can give rise to an adverse feedback loop between financial markets and the real economy. Overcoming these deficiencies in our knowledge will not be easy, but the potential benefits could be great. Finally, as I emphasized at the outset, we must thoroughly review the regulatory structure of the U.S. and global financial systems, with the objective of both identifying and implementing the comprehensive changes needed to reduce the odds of future bubbles arising, and improving the ability of banks and other financial institutions to weather the fallout from unexpected adverse changes in asset prices. Ultimately, this process should prove our best line of defense against the problems of the sort we now face. 


\section{Speech by Jeffrey M. Lacker, 3rd of December 2008. Estimated as indicating a very hawkish stance on CPI, given all other economic indicators at that time:}

These are economically trying times. In my remarks, I would like to discuss the factors I see affecting the outlook for the U.S. economy and monetary policy. As always, I speak only for myself, and not for my Federal Reserve System colleagues.1 Financial market conditions loom large in any discussion of the economy these days. The heart of the problem, of course, is the home mortgages made from late 2005 through early 2007, near the end of the long U.S. housing boom that began in 1995. Since the peak in activity in 2005 , housing investment has fallen by more than 40 percent. Average housing prices, as measured by the FHFA repeat sales index, have fallen 6 percent since their peak in April 2007. Some markets have experienced more dramatic declines; the home price index for California fell 18 percent, for example. The resulting erosion in home equity for many borrowers has meant that mortgages made near the peak of the boom, especially the subprime and non-traditional categories, are experiencing much larger losses than expected. It will take years of research to untangle the quantitative contribution of various causal factors to the rise in subprime mortgage lending and the increase in subprime losses, so I wont attempt such an analysis here. Let me simply offer a list of plausible suspects. One candidate is the wave of technological innovation in retail credit delivery, which contributed to an expansion of consumer credit, including unsecured and mortgage credit. As in any industry in the midst of innovation, this expansion may have involved overshooting and retrenchment. A second suspect is the regulatory and supervisory framework surrounding U.S. housing finance, which may have been insufficiently prepared for the possibility of a swing in housing demand of the magnitude and geographic extent that we have seen. Private sector incentives to foresee and protect against such shocks were to some extent dampened by the presence of the federal financial safety net, and perhaps by official policies aimed at increasing homeownership. In addition, the unscrupulous and fraudulent practices of some mortgage brokers outside of the banking sector may have contributed to the problem. I would also cite relatively low interest rates after the recession earlier this decade, especially in 2003 and 2004. Some economists have argued, with the benefit of hindsight, that tighter monetary policy during that period would have led to better outcomes by preventing core inflation from rising, thus limiting the housing boom and mitigating the subsequent bust.2 While I find this view plausible, again, further research will be required to substantiate this hypothesis. That's all prologue, however, to the turmoil that has plagued financial markets since the middle of last year, when the potential scale of the home mortgage problem became more widely appreciated. The turmoil intensified in mid-September this year, and volatility has been elevated since. Financial market participants have faced three major categories of uncertainty. The first concerns the aggregate amount of losses on mortgage lending. For mortgages made in 2006 and early 2007 the vintages in which losses are concentrated significant uncertainty still remains regarding total losses. Second, financial market participants face uncertainty about where the losses will turn up. Mortgage risks were split up and spread widely, both within the United States and in Europe, through securitization and use of the insurance capabilities provided by credit derivative contracts. As a result, financial market participants are understandably apprehensive about whether a particular counterpartys mortgage-related losses will erode their capital buffer enough to threaten their viability. This has led to elevated risk premia in interbank credit markets for institutions with at least some presumed mortgage-related exposure. Third, market participants have at times faced uncertainty about prospective public sector intervention. 3 The disparate responses to potential failures at several high-profile organizations this year may have made it difficult for market participants to forecast whether and in what form official support would be forthcoming for a given counterparty. Shifts in expectations regarding official intervention may have added volatility to financial asset markets that already were roiled by an increasingly uncertain growth outlook. The striking feature of central bank lending during the recent turmoil is the extent to which it has extended well beyond the boundaries that previously were understood to constrain such lending, both in the range of institutions and the contractual terms on which credit has been provided. Intervention has been driven by a desire to prevent damaging disruptions to financial markets, and thus reduce the overall costs of the turmoil. While this objective is clearly understandable, central bank lending can create the expectation 
that similar support will be forthcoming when market disruptions occur in the future. Such expectations can themselves be very costly, because they can distort the incentives faced by, and as a result, the choices made by private-sector participants. The critical policy question of our time is where to establish the boundaries around the public-sector safety net provided to financial market participants, now that the old boundaries are gone. In doing so, the prime directive should be that the extent of regulatory and supervisory oversight should be commensurate with the extent of access to central bank credit in order to contain moral hazard effectively. The dramatic recent expansion in Federal Reserve lending, and government support more broadly, has extended public sector support beyond existing supervisory reach, and thus could destabilize the financial system, if no corrective action is taken. Restoring consistency between the scope of government support and the scope of government supervision is essential to a healthy and sustainable financial system. One option is simply to adapt our regulatory and supervisory regime to the new wider implied reach of government lending support. This strikes me as an unattractive option, if for no other reason than the current uncertainty about the outer bounds of that support. Constraining moral hazard in such a regime would be an immense and daunting task. I take it as given, therefore, that the scope of financial safety net ultimately must be rolled back. Note that it will not be sufficient simply to roll back the current lending programs when the economy recovers. The precedents that have been set during this episode will influence how market participants expect policymakers to react during the next episode of financial market turmoil. Establishing a coherent and stable financial regulatory regime will require rolling back expectations about how the policymakers will respond to the next financial market disturbance. Rolling back those expectations will be impossible if moral hazard concerns are always set aside in the exigencies of a crisis.4 Assessing the effects of financial market turmoil on real economic spending is not as straightforward as it might seem. One popular notion is that the credit market disruptions weve seen over the last year or so impede the financial sectors ability and willingness to extend credit to households and business firms, thereby creating an additional drag on spending. But causation can flow in the opposite direction as well. When overall economic activity seems poised to contract, the outlook for household income and business revenues deteriorates as well, and such borrowers become less creditworthy, all else constant. My reading of current conditions is that bank lending is constrained more now by the supply of creditworthy borrowers than by the supply of bank capital. The decline in U.S. housing activity since early 2006 has affected not only credit markets it has had a significant impact on broader economic activity as well. For a time, the weakness was isolated in the housing market, as the rest of the economy continued to expand at a relatively healthy rate. But late last year, consumer spending began to slow. Household net worth has declined as home prices have fallen virtually nationwide over the last year-and-a-half, and, more recently, equity prices have slumped. Increases in energy prices up through the middle of this year took a substantial bite out of real incomes. Moreover, payroll employment peaked last December, and has since shed 1.2 million jobs. As the labor market has weakened, wage growth has tapered off. Except for the temporary bulge due to the stimulus payments earlier this year, real personal income has steadily decelerated, and is now below where it was a year ago. Given this catalog of adverse developments for U.S. households, it should be no surprise that consumer spending was sluggish in the first half of the year and has fallen significantly in recent months. When household spending slows substantially, business capital investment is usually not far behind. Business spending on equipment and software fell in the first half of 2008, and the near-term outlook is not favorable. Many firms are facing dimmer sales prospects, higher funding costs, and more restrictive borrowing terms. The other segment of business fixed investment, spending on new structures, has been booming recently. In 2007 and the first half of 2008, real nonresidential fixed investment a segment that includes office buildings, hotels, malls and the like grew at a 14 percent annual rate. That category seems to have topped out over the summer, and is certain to decline in coming months. Foreign trade has added significantly to GDP growth last year and the first half of this year. Unfortunately, the trade contribution to U.S. growth is likely to decline in the near term in response to diminishing world growth prospects and the recent strength in the dollar. Two days ago, the National Bureau of Economic Research officially confirmed what virtually all economists already knew namely, that a recession began last December when payroll employment peaked. For a time, the decline was fairly mild in fact milder than the last two recessions, 
both of which were themselves mild by historic standards. But conditions downshifted dramatically sometime in September, just as financial market turmoil was accelerating. Since then, according to reports, many households and firms are taking a wait and see attitude, reducing or postponing nonessential outlays in response to a general sense of uncertainty about the potential meaning of these dramatic events for their own economic circumstances. A wide array of economic indicators has deteriorated markedly since then as well. Looking ahead, uncertainty about the outlook is greater than usual, though probably not greater than is typical for this phase of a business slowdown. It strikes me as reasonable to expect the U.S. economy to regain positive momentum sometime in 2009 , for several reasons. First, monetary policy is now quite stimulative. Second, the energy and commodity price shocks that dampened economic activity earlier this year have subsided already or are in the process of doing so. And as Ive mentioned, the drag from housing seems likely to lessen in the next year, and in fact, I would be surprised if we dont see a bottom in housing construction sometime in 2009. This is the third straight year, however, that Ive been expecting a bottom in the housing market in the middle of next year, so my outlook is tempered by more than the usual amount of humility. While the downturn in real economic activity is going to pose challenges for monetary policy in the period ahead, its essential that we not let inflation drift from view. Since 2004, overall inflation has trended upward, and has been higher than I would like, over the last few years. Much of the acceleration we saw earlier this year reflected energy prices, however, and with oil prices down we have seen overall inflation subside in recent months. Many economists are forecasting relatively low inflation in the months ahead, on the grounds that widening economic slack is generally associated with declining price pressures. While this correlation is detectable in many datasets, I would be cautious about relying on it as a causal relationship.5 And while it may seem premature to be worrying about how inflation behaves after the recession is over, we need to be sure our policy remains consistent with a strategy that does not allow inflation to ratchet up over the business cycle. As I said at the outset, these are not the best of economic times. We have weathered economic downturns before, however, both nationally and globally. And there is no sign that the fundamental creative process that drives innovation and improves well-being over time has been mortally wounded. What sets this episode apart is the nature of the turmoil plaguing the financial sector, and the array of unprecedented government lending programs. While navigating the slowdown in real economic growth is a challenge, the larger and more significant challenge will be to re-establish the boundaries around central bank lending and public sector support and reconstruct the relationship between the public sector and financial markets. How well we meet this challenge will determine the extent to which innovation, despite the associated volatility, will continue to contribute to the effectiveness of our financial system and to overall economic growth. 